\title{
Letter
}

\section{The Humane Research and Testing Act: Advancing Science by Creating a New Center for Alternatives at the US National Institutes of Health}

\author{
Paul A. Locke', Mikalah Singerl and Thomas Hartung ${ }^{2,3}$ \\ ${ }^{1}$ Johns Hopkins Bloomberg School of Public Health, Department of Environmental Health and Engineering, Baltimore, MD, USA; ${ }^{2}$ Center for Alternatives \\ to Animal Testing (CAAT), Johns Hopkins Bloomberg School of Public Health, Baltimore, MD, USA; ${ }^{3}$ CAAT-Europe, University of Konstanz, Germany
}

On March 8, 2021, a congressional briefing on $21^{\text {st }}$-century innovation in alternatives to animals in biomedical research and the Humane Research and Testing Act (HRTA) was held. The briefing was sponsored by the late Representative Alcee Hastings (D-FL) and Representative Vern Buchanan (R-FL) and featured five experts who share a range of perspectives on the HRTA of 2020. The speakers included Dr Jane Goodall, an international expert on primates, whose organization, The Jane Goodall Institute, hosted the virtual briefing. The other speakers included Dr Donald Ingber, founder of the Wyss Institute for Biologically Inspired Engineering at Harvard University, Dr Azra Raza, Professor of Medicine at Columbia University, and two of the authors of this article, Dr Paul Locke, a lawyer and public health scientist who is an Associate Professor at the Johns Hopkins Bloomberg School of Public Health, and Dr Thomas Hartung, Director of the Center for Alternatives to Animal Testing at Johns Hopkins University.

The briefing provided an opportunity for interested parties to discuss the bill and address questions and comments from the audience. The speakers endorsed the passage of the HRTA, pointing out ethical, legal, and scientific reasons for their support of the legislation.

Dr Goodall noted the important ethical and moral issues that arise when animals become research subjects and pointed out that scientists must meet an extremely high standard when using animals. Her experience demonstrated that animal use in research should be avoided whenever possible and that new methods to replace animals are needed immediately. Dr Locke pointed out that the HRTA was evolutionary, not revolutionary, in its intent and approach and that it matches well with current laws and policies. Dr Ingber provided information about how microphysiological systems can mimic human organs and their functions, providing a fertile area of advancement for alternatives (Ingber, 2020). Dr Raza shared her clinical experience with the audience, noting that the treatments for diseases such as cancer had changed little in the past three decades. New treatment tools are desperately need- ed, and current animal-based research is not leading to advances that she can bring to her patients to improve their outcomes. Dr Hartung noted that animal models are hitting certain limits, and alternative models can be used to help science when barriers are met. He noted that his laboratory utilized a three-dimensional human-inspired "mini-brain" model to rapidly examine the potential passage of COVID-19 into brain tissue (Bullen et al., 2020).

\section{What would the HRTA change?}

Two days later, on March 10, 2021, the HRTA was introduced before the US House of Representatives by the late Representative Alcee Hastings (D-FL). It is dedicated to funding and incentivizing scientists to develop and use alternative methods to replace animal models and to create a focal point in the National Institutes of Health $(\mathrm{NIH})$ complex for innovative new methods (HRTA, 2020; Stagno, 2021). This bill would establish a new National Center for Alternatives in Research and Testing under the $\mathrm{NIH}$, and it would require the NIH to track and disclose the total number of animals being used across the NIH research complex.

The HRTA builds on requirements that have already been enacted into US law by the National Institutes of Health Revitalization Act (1993), which established an oversight system that required the NIH to outline a plan for reducing the number of animals used in research, as well as "conduct or support research into ... methods of biomedical research and experimentation that do not require the use of animals" (Stagno, 2021).

The Director of the new center would be tasked with providing assistance, including funding, to researchers in order to incentivize the development and use of research and testing methods, train and provide information on the available methods, and establish communication channels for scientists to collaborate on method use and development. The HRTA specifies certain methods including microphysiological systems, advanced cell cultures like 3D organoids, and in silico models as candidates for future development.
Received June 3, 2021;

(C) The Authors, 2021.

ALTEX 38(4), 678-680. doi:10.14573/altex.2106031

Correspondence: Paul A. Locke, JD, DrPH

Johns Hopkins Bloomberg School of Public Health Department of Environmental

Health and Engineering

615 North Wolfe Street, Baltimore, 20105, MD, USA

(plocke@jhu.edu)
This is an Open Access article distributed under the terms of the Creative Commons Attribution 4.0 International license (http://creativecommons.org/licenses/by/4.0/), which permits unrestricted use, distribution and reproduction in any medium, provided the original work is appropriately cited. 
In addition to providing a focal point for scientists to collaborate and assist others working on alternative models, the center would also make the information on the number of animals used in federally funded research publicly available and develop a plan for reducing the number of animals used in federally funded research and testing. Currently, the total number of animals used in federally funded research and testing is not counted (Taylor and Rego Alvarez, 2019; Busquet et al., 2020). The process that would be implemented by the new center would increase transparency for the public, as well as for the scientific community. By having the information available, the public will be more aware of the research that is being conducted using animal models.

The collaborative aspect of this legislation is intended to help scientists who may not have access to the tools to work on alternatives, as well as provide information about alternative methods to the public to increase overall awareness of these techniques. It is anticipated that as information about these methods is made more widely available, the scientific community will have more opportunity to use them. In addition, interested members of the public will be made aware of alternative methods.

The HRTA does not prohibit or discourage animal-based research. It does seek to advance methods that do not rely on animals. Its intent is to assist in strengthening the tools available to the scientific community with an eye toward addressing complex human biological pathways of disease. To better protect human and environmental health, research and testing models should expand to include alternatives that track human biology as closely as possible.

\section{How does the HRTA fit in with existing federal laws?}

The congressional briefing presented an opportunity to speak about the implications of the HRTA under US federal law. While it is not possible to dictate how science progresses, it was generally agreed by the speakers that having a federally funded organization dedicated to the development and use of alternatives would help to encourage the use and development of new methods that are more directly relevant to humans and that better public health protection will come from scientific methods that best recapitulate human biology.

In addition, not only would the proposed center provide accountability within the NIH and federal government, but it would increase transparency for all interested parties. Additional transparency could lead to greater confidence among stakeholders, who are concerned about marshalling the best science for health protection. A federally funded center that looks at alternatives will be a focal point for the public, stakeholders, and scientists to look to and learn about the development and use of alternative models. As Dr Ingber noted, the more people are aware of the available technology, the more it will become accepted and utilized.

Most significantly, this center is not only important because of its potential for research and human health development, but because there is no US federal law or regulation that directly incentivizes the development of alternatives. Currently, there is nothing that provides the resources necessary for these methods to be developed. The existing laws that address alternatives focus only on their ability to be used if they exist and if they are scientifically appropriate. The HRTA fills this gap by providing funding and a federal space for collaboration.

The NIH Revitalization Act (1993) previously directed the NIH to support research to replace, reduce, and refine animal use in biomedical research and to develop and validate alternatives to animal use for accurate and chronic safety testing. The NIH Revitalization Act led to the ICCVAM Authorization Act (2000), which created a permanent interagency coordinating committee to increase the effectiveness of federal agency test method review, the reduction, refinement, and replacement of the use of animals in testing where feasible, and optimization of scientific expertise outside of the US federal government, among other things. The HRTA would help support the NIH meet their already established requirements of the 1993 Act.

While the Animal Welfare Act (AWA) includes provisions that govern the use of certain animals in research and testing, this federal law excludes rats, mice and birds bred for research purposes (Animal Welfare Act, 2013). However, these categories of animals, particularly rodents, comprise the majority of the animals used in testing and research (The Hastings Center, 2013). The AWA requires U.S. Department of Agriculture (USDA)-registered research facilities and federal research facilities to submit an annual report that documents their use of animals. These reports are not exhaustive as they do not include mice, rats, or birds since those species are excluded from the definition of "animal" under the AWA. The HRTA would include those species currently excluded from the reports and require such reporting by all research facilities that receive federal funding, but not privately funded research and research facilities.

\section{Are there concerns about the HRTA?}

While the HRTA has laudable goals, the speakers noted that there are several areas that could use improvement. At the time of the briefing, the proposed bill, and the previous iteration of the bill from 2020, did not include a definition section to define the term "animal." Speakers noted it would be a very valuable inclusion and that the definition should build on the definition of "animal" in both the Animal Welfare Act (2013) and the Health Research Extension Act (1985), as well as extend it to include rats, mice and birds bred for research purposes. A harmonized definition would streamline conversations about implementation and make the process smoother. On March 10, when the bill was introduced, a definition of "animal" was included as "any vertebrate" and "includes all warm-blooded and cold-blooded species" which is more inclusive than the existing definition of animal in the AWA. Notably, this is still less inclusive than the European legislation, which additionally includes cephalopods and unborn vertebrates of the last trimester (Hartung, 2010).

Furthermore, it would be valuable to add an additional purpose that would call for the center to lead a national effort to develop alternatives in areas where animal models have not been available, especially where progress in developing treatments and cures for diseases and understanding their causes has stalled. Adding this goal would have the potential to improve the health of populations that are not being well served by current research initiatives. 
Despite the support shown by the range of speakers at the congressional briefing, the HRTA is not without critics, and several opponents to the bill offered their perspectives during the question-and-answer session of the briefing and in other venues. Opponents of the HRTA believe that the passage of the bill is based on a misunderstanding about animal models, claiming that proponents of the bill are trying to shut down animal research by alleging that animal models are not now, and will not be in the future, necessary for biomedical research. One opposition group stated that this bill "appear[s] to create a ready-made animal rights targeting lists through further mandatory reporting and [is] aimed at eliminating animal models rather than helping the research community validate truly effective methods" despite also claiming that they support "valid and effective animal alternatives." (American Association for Laboratory Animal Science, 2021). This is a central tenet that those who oppose the bill have echoed.

Opponents of the bill also claim that a new center on alternatives and additional reporting requirements are simply an attack on animal research rather than a support of human-centric research. It is important to reiterate that should the bill become law, it will establish a center focused on alternative models within the $\mathrm{NIH}$, but no language in the bill diminishes the role animal models have played in human and environmental health protection. It is true that the bill would impose additional reporting requirements on the NIH, but the NIH already obtains much of this information from facilities, though it is not currently made available to the public.

\section{Summary}

If enacted into law, the Humane Research and Testing Act would be a positive step forward in advancing non-animal models and human-based biological techniques. The establishment of a new $\mathrm{NIH}$ center will help foster research into alternatives that can be used to fill in the gaps in our understanding of the underlying processes that lead to disease. The new center will also provide funding and opportunities for researchers working on new technology to incentivize additional research and act as a focal point for replacement alternatives expertise and knowledge.

The HRTA could be an effective complement to laws such as the Frank R. Lautenberg Chemical Safety Act (2016) to encourage the use of non-animal methodologies in toxicity testing, as well as help overcome barriers preventing the use of alternative models in basic research. Such barriers include the creation and availability of alternative techniques, the awareness of new methods, and the transparency surrounding alternative models (Gruber and Hartung, 2004). The HRTA addresses each of those issues by creating a place for researchers to collaborate and produce information that can be used to help meet the reduction and replacement requirements of laws like the Lautenberg Act.

Creating structures that will allow for the funding and development of alternatives will inspire researchers to become aware of, and to use, modern technologies which have greater potential to identify key human disease pathways and endpoints. Recogniz- ing the need and value of this new center does not diminish what animal models have done for human and environmental health, just as the HRTA does not take away from animal research. This legislation simply creates a new center to expand opportunities. It would serve as a way to incentivize innovative methods to tackle $21^{\text {st }}$-century health problems.

\section{References}

American Association for Laboratory Animal Science (2021). Tell Congress to OPPOSE Humane Research and Testing Act of 2021. https://www.ncabaalas.org/News-Feed/10232252

Animal Welfare Act (2013). 7 U.S.C. Sec. 2132g, https://www.gov info.gov/content/pkg/USCODE-2013-title7/pdf/USCODE2013-title7-chap54.pdf

Bullen, C. K., Hogberg, H. T., Bahadirli-Talbott, A. et al. (2020). Infectability of human BrainSphere neurons suggests neurotropism of SARS-CoV-2. ALTEX 37, 665-671. doi:10.14573/ altex.2006111

Busquet, F., Kleensang, A., Rovida, C. et al. (2020). New European Union statistics on laboratory animal use - What really counts! ALTEX 37, 167-186. doi:10.14573/altex.2003241

Frank R. Lautenberg Chemical Safety for the $21^{\text {st }}$ Century Act (2016). HR 2576. https://www.congress.gov/114/plaws/ publ182/PLAW-114publ182.pdf

Gruber, F. P. and Hartung, T. (2004). Alternatives to animal experimentation in basic research. ALTEX 21, Suppl 1, 3-31. https:/www.altex.org/index.php/altex/article/view/2182

Hartung, T. (2010). Comparative analysis of the revised Directive $2010 / 63 / \mathrm{EU}$ for the protection of laboratory animals with its predecessor 86/609/EEC - $\mathrm{At}^{4}$ report. ALTEX 27, 285-303. doi:10.14573/altex.2010.4.285

Hastings Center (2013). Animals used in research in the U.S. http://animalresearch.thehastingscenter.org/facts-sheets/ animals-used-in-research-in-the-united-states/

Health Research Extension Act (1985). HR 2409. https://www. congress.gov/99/statute/statute-99/statute-99-Pg820.pdf

Humane Research and Testing Act (2020). HR 8633. https://www. congress.gov/bill/116th-congress/house-bill/8633?s=1\&r=18

ICCVAM Authorization Act (2000). HR 4281. https://ntp.niehs. nih.gov/iccvam/docs/about_docs/pl106545.pdf

Ingber, D. (2020). Is it time for reviewer 3 to request human organ chip experiments instead of animal validation studies? Advanced Sci 7, 2002030. doi:10.1002/advs.202002030

National Institutes of Health Revitalization Act (1993). PL 10343, Sec. 205, https://www.congress.gov/103/statute/statute107/statute-107-Pg122.pdf

Stagno, B. (2021). Let's pass the Humane Research and Testing Act of 2021. https://www.caareusa.org/let_s_pass_the humane_research_and_testing_act_of_2021

Taylor, K. and Rego Alvarez, L. (2019). An estimate of the number of animals used for scientific purposes worldwide in 2015. Altern Lab Anim 47, 196-213. doi:10.1177/0261192919899853 